\title{
The effectiveness of the Uchida-Kraepelin test for psychological stress: an analysis of plasma and salivary stress substances Koreaki Sugimoto*1, Aya Kanai ${ }^{1}$ and Noriaki Shoji ${ }^{2}$
}

Address: ${ }^{1}$ Division of Psychosomatic Medicine and Oral Medicine, Tohoku Fukushi University, Sendai, Japan and ${ }^{2}$ Division of Oral Diagnosis, Tohoku University Graduate School of Dentistry, Sendai, Japan

Email: Koreaki Sugimoto* - k-s@umin.ac.jp; Aya Kanai - ak23312000@yahoo.co.jp; Noriaki Shoji - tiger@mail.tains.tohoku.ac.jp

* Corresponding author

Published: 3 April 2009

BioPsychoSocial Medicine 2009, 3:5 doi:10.1 186/1751-0759-3-5

This article is available from: http://www.bpsmedicine.com/content/3/l/5

(c) 2009 Sugimoto et al; licensee BioMed Central Ltd.

This is an Open Access article distributed under the terms of the Creative Commons Attribution License (http://creativecommons.org/licenses/by/2.0), which permits unrestricted use, distribution, and reproduction in any medium, provided the original work is properly cited.
Received: 29 September 2008

Accepted: 3 April 2009

\begin{abstract}
Background: The hypothalamic-pituitary-adrenocortical (HPA) axis and sympathetic adrenomedullary (SAM) system are the major stress-response pathways. Plasma adrenocorticotropic hormone $(\mathrm{ACTH})$ represents HPA axis activity, while plasma catecholamines are used as markers of the SAM system. Salivary alpha amylase (AA), chromogranin A (CgA), and immunoglobulin $A(\lg A)$ are candidate markers of stress activation, although their role has not been established. The Uchida-Kraepelin (U-K) test is a questionnaire that requires intense concentration and effort, and has been used as a tool to induce mental stress. However, it is not clear whether or not the test is effective as a psychological/mental stressor.
\end{abstract}

Methods: In this study, normal young women took the U-K test and serial measurements of plasma ACTH and catecholamines (dopamine, noradrenaline, and adrenaline) $(n=10)$, as well as salivary $\mathrm{AA}, \mathrm{CgA}$, and $\lg A(n=16)$ before, during and after the test.

Results: We found no changes in any of these parameters at any time point during or after the $U$ $\mathrm{K}$ test.

Conclusion: Our findings indicate that the $\mathrm{U}-\mathrm{K}$ test is not a suitable for measuring the psychological/mental stress of young women because the plasma data showed that it did not affect the HPA axis and SAM system. The U-K test should be employed carefully as a psychological/mental stressor due to insufficient scientific evidence of its effectiveness. In addition, salivary $A A, C g A$, and IgA should not simply be compared with previous reports, because the mechanism of secretion and normal range of each salivary parameter remain unknown. Salivary AA, CgA, and IgA may not be suitable candidate markers of psychological/mental stress.

\section{Background}

The Uchida-Kraepelin (U-K) test is a questionnaire modified from the Kraepelin's arithmetic test, which was originally developed by Y. Uchida [1]. The U-K test measures the ability of takers on task performance speed and task performance accuracy. The results of the U-K test provide an estimate of the individual's character. The U-K test requires focused effort and attention by the subject, making this test useful for the assessment not only of character but also of mental stress [2,3]. In fact, it has been used 
widely to assess work aptitude as a mental stressor [2,412]. However, it is not clear whether or not the U-K test per se provides psychological/mental stress to its taker.

Homovanillic acid (HVA) is a major metabolite of dopamine $[11,12]$, and 3-methoxy-4-hydroxyphenylglucol (MHPG) is a metabolite of noradrenaline [3]; both have been used as markers of stress incurred by the U-K test. However, serum catecholamines; dopamine (DA), noradrenaline (NA) and adrenaline (AD) have not been measured as stress markers, although excitement up-regulates these molecules, especially $\mathrm{NA}$ and $\mathrm{AD}$, through the sympathetic nervous system [7,13-16]. Likewise, the HPA axis marker adrenocorticotropic hormone (ACTH) has not been used as a marker of psychological/mental stress in a U-K test study, although the hypothalamic-pituitaryadrenocortical (HPA) axis is also known to be stimulated by various stressors $[7,15,16]$.

Salivary fluid is often sampled for biological assays because of ease and noninvasive accessibility. Several salivary markers have been proposed as biological markers of psychological stress in humans, including salivary $\alpha$ amylase (sAA) $[2,7,17-24]$, salivary chromogranin A (sCgA) [25-29], and salivary immunoglobulin A (sIgA) [27,30-36]. However, none are yet established as routine stress markers.

In the present study, we measured plasma ACTH, DA, NA and $\mathrm{AD}$ to investigate the effects of the U-K test applied as a psychological/mental stressor on the HPA axis and sympathetic adrenomedullary (SAM) system. We also examined the effects of the U-K test on $\mathrm{sAA}, \mathrm{sCgA}$, and sIgA secretion.

\section{Methods}

\section{Participants and experimental design}

A total of 19 healthy young women (age, 19 to 23 years) participated in the present study. None were on medication, had bouts of gingivitis, drank alcohol more than twice per week, smoked or was pregnant. Figure 1 shows the study design. On the day of the study, the volunteers had lunch then rinsed their mouth and rested for $60 \mathrm{~min}$, after which they abstained from food and drink. Saliva was collected from 16 volunteers and blood was collected from 10 volunteers before, during and after the U-K test presented on a compact disc player (Japan Psychiatric Technology Institute Inc.) in the afternoon between 2 and 3 PM. All saliva and blood samples were taken at the same time of the day for each volunteer.

The U-K test is a serial addition test, which requires takers to perform calculations as fast and accurately as possible within $30 \mathrm{~min}$. This was achieved using pre-printed paper containing 15 lines of random, single-digit, horizontally aligned numbers. For each minute of the test, the subject was instructed to begin a new line regardless of their position on the current line. Each line contained an excess of calculations such that the subjects were not able to finish any line for a particular minute before being prompted to move on to the start of the next minute by the examiner's prompting. This test is usually performed for repeated 15 min of work and 5 min rest cycles.

To investigate the participants' character, the MOS 36Item Short-Form Health Survey (SF-36) [37] was given to all participants before the U-K test. SF-36 version 2 includes scales for physical functioning, physical role, bodily pain, social functioning, general health perceptions, vitality, emotional role, and mental health. This SF36 can be used to check health-related quality of life. Furthermore, the data of the U-K test of each participant was correlated with each character and with plasma and salivary stress substances. The character results obtained by the U-K test are composed of behavioral activation, mood or behavioral variation, behavioral sensitivity, character or behavioral deviation/tendency, and total typical/atypical manner.

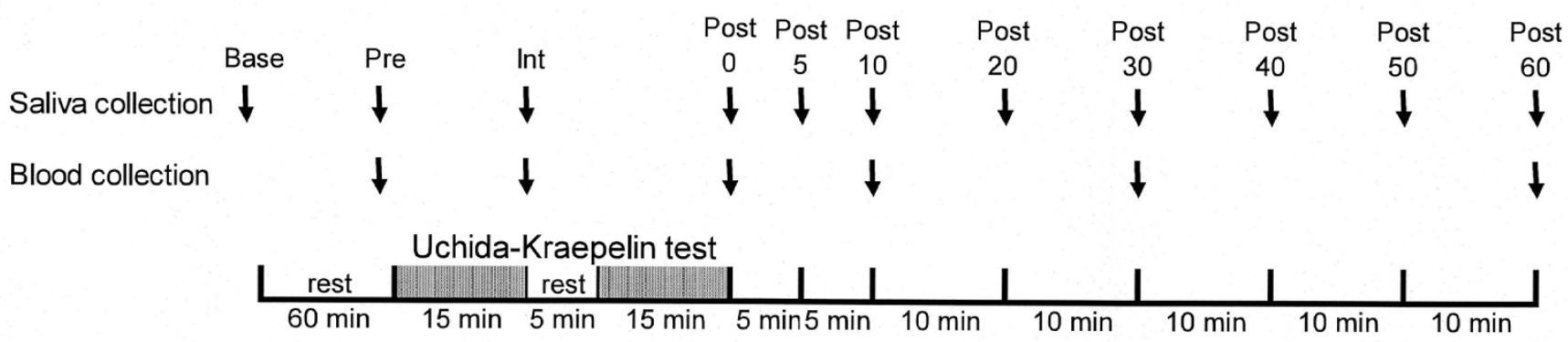

Figure I

Experimental design. Saliva and blood samples were collected at II and 6 different time points, respectively, both each 5 min. Arrows indicate the start point of collecting. 
The Ethics Committee of Tohoku Fukushi University approved the study protocol. The study was carried out in compliance with the Helsinki Declaration. All participants were fully briefed on the scope of the experiment, and informed consent with oral explanation and written documents was obtained from each participant prior to the study.

\section{Measurements of plasma ACTH, dopamine, noradrenaline, and adrenaline levels}

A cannula was inserted in a vein of the left arm and maintained via a heparin-saline lock system $3 \mathrm{~h}$ before undergoing the U-K test. Four $\mathrm{ml}$ of blood was collected over 5 min via the cannula immediately before, during, and at 0 , 10,30 , and $60 \mathrm{~min}$ after the test. Plasma was prepared and assayed for ACTH by radioimmunoassay (RIA kit RK-00101, Phoenix Pharmaceuticals Inc, Burlingame, CA), while $\mathrm{DA}, \mathrm{NA}$, and $\mathrm{AD}$ concentrations were estimated by highperformance liquid chromatography (HPLC).

\section{Saliva collection and salivary flow rate calculation}

Saliva was collected by the spitting method, which involves collecting spontaneous/passive drooling saliva, at baseline (at the start of the rest period), immediately before, during, and at 0, 5, 10, 20, 30, 40, 50, and $60 \mathrm{~min}$ after the test. Saliva was collected over $5 \mathrm{~min}$ and kept on ice. Samples were centrifuged at 1,500 $\times g$ for $15 \mathrm{~min}$ and the supernatant used for $\mathrm{CgA}$ and $\mathrm{IgA}$ measurements. The remainder was stored frozen at $-80^{\circ} \mathrm{C}$ until further use The amount of collected saliva in grams was converted to milliliters assuming that the specific gravity of saliva is $1.01(\mathrm{~g} / \mathrm{ml})$; this value was divided by 5 to ascertain the salivary flow rate in $\mathrm{ml} / \mathrm{min}$.

\section{Salivary $\alpha$-amylase, chromogranin A, and immunoglobulin A assays}

Salivary AA was measured using a Cocoro meter ${ }^{\circledR}$ (Nipro Co, Osaka, Japan) $[7,38]$ within 2 min after sampling. The meter tip was immersed in saliva under the tongue of the subject for $30 \mathrm{sec}$ starting from 1.5 through $2 \mathrm{~min}$ after each time point of saliva collection. This amylase monitor uses a dry chemistry system, measuring enzymatic activity in a batch type, and using a reagent paper containing the amylase substrate, 2-chloro-4-nitrophenyl -4-O- $\beta$-Dgalactopyranosylmaltoside (Gal-G2-CNP, Toyobo Co, Tokyo).

$$
\text { Gal }-\mathrm{G} 2-\mathrm{CNP} \underset{\alpha \text {-amylase }}{\longrightarrow} \mathrm{Gal}-\mathrm{G} 2+\mathrm{CNP}(\text { white } \rightarrow \text { yellow })
$$

Amylase hydrolyzes the Gal-G2-CNP present in the reagent paper to produce a color change from white to yellow, measured optically for $30 \mathrm{sec}$. One unit of $\alpha$-amylase activity (U) was defined as the enzymatic activity that could produce reduced sugar equivalent to $1 \mu \mathrm{mol}$ mal- tose at $37^{\circ} \mathrm{C}$ in $1 \mathrm{~min}$. Salivary AA was expressed in $\mathrm{U} / \mathrm{ml}$ [38].

Salivary CgA and IgA were measured by enzyme immunoassay (EIA) using the YKO human chromogranin A EIA kit (Yanaihara Institute Inc $^{\circledR}$ ) and salivary secretory IgA indirect enzyme immunoassay kit (Salimetrics LLC Inc, State College, Pennsylvania, USA). This IgA kit measured salivary IgA within the range of $379.39 \pm 261.47 \mu \mathrm{g} / \mathrm{ml}$, $($ mean $\pm \mathrm{SD}, \mathrm{n}=21)$.

\section{Statistical analysis}

Data are expressed as mean \pm SD. All data were analyzed by one-way analysis of variance (ANOVA) followed by Tukey's test. Sample numbers are 10 for blood samples and 16 for salivary samples. A $P$ value less than 0.05 denoted the presence of a statistically significant difference.

\section{Results \\ The U-K test does not influence plasma ACTH concentration}

To examine the effect of the U-K test on the HPA axis, plasma ACTH was measured. Plasma ACTH seems to be more sensitive than plasma cortisol to stress on the HPA axis [39]. Plasma ACTH concentrations before, during, and after the U-K test are shown in Figure 2[A] $(n=10)$. There was no significant change from the standard range in mean ACTH values during or after the U-K test $[d f=5$, $F$-value $=1.27, P=0.29]$.

The U-K test does not influence plasma noradrenaline, dopamine, and adrenaline concentrations

To examine the effect of the U-K test on the SAM system, plasma levels of NA, DA, and AD. Plasma NA, DA, and AD concentrations measured before, during, and after the U$\mathrm{K}$ test are shown in Figure [ $2 \mathrm{~B}$ and $2 \mathrm{C}]$. There were no significant changes from the standard range of each catecholamine in NA, DA, and AD values during or after U-K test. Plasma NA: $[d f=5, F$-value $=0.27, P=0.93]$. Plasma DA: $[d f=5, F$-value $=1, P=0.43]$. Plasma AD: $[d f=5, F$-value $=0.66, P=0.65]$.

\section{The U-K test does not influence salivary flow rate}

To rule out a possible effect of the volume of secreted saliva, salivary flow rate $(\mathrm{ml} / \mathrm{min})$ was measured. The flow rate of salivary secretion is known to influence sAA, sCgA, and sIgA concentrations $[22,40]$. Salivary flow rates before, during, and after the U-K test are shown in Figure 3. No significant differences in flow rate were observed in this study $[d f=10, F$-value $=0.21, P=0.99]$. Although the variability in salivary flow rate was large among individuals, we could neglect the effect of salivary secretion statistically. 

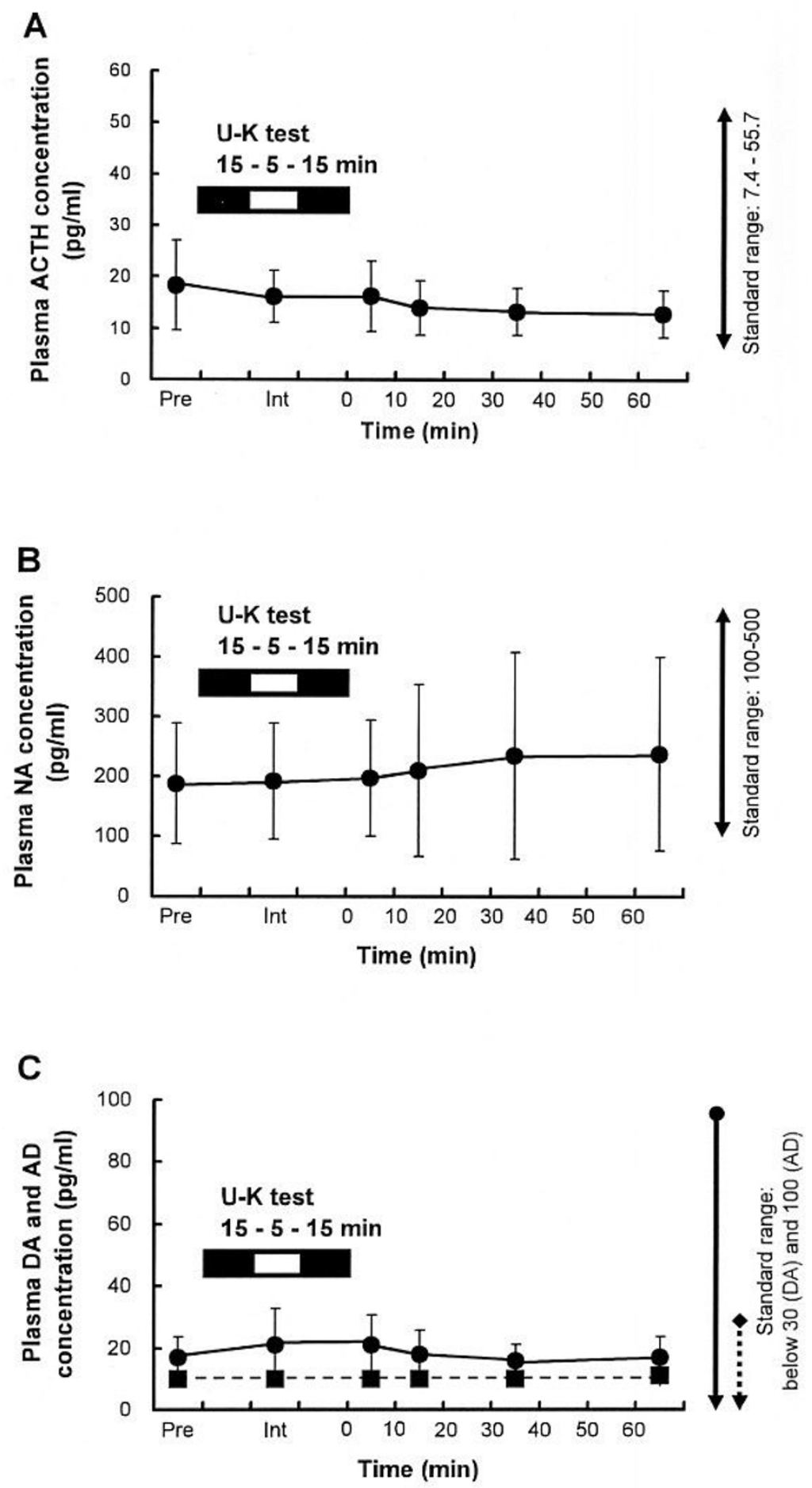

Figure 2

Plasma concentrations of $[A]$ ACTH, $[B]$ noradrenaline, $[C]$ dopamine and adrenaline before and after the $U$ K test. Plasma ACTH, NA, AD (solid line), and DA (dotted line) concentrations (pg/ml) before, during, and after the U-K test are shown as mean $\pm S D(n=10)$. Pre: immediately before the test; int: during the test; 0, 10, 30, 60 min: minutes after completion of the U-K test. Standard ranges of plasma ACTH, DA, AD, and NA represent the reference ranges (ACTH: 7.4-55.7; NA: 100-500; $D A<30, A D<100, \mathrm{pg} / \mathrm{ml}$, respectively), not the normal range. U-K: Uchida-Kraepelin, NA: noradrenaline, DA: dopamine, AD: adrenaline. 


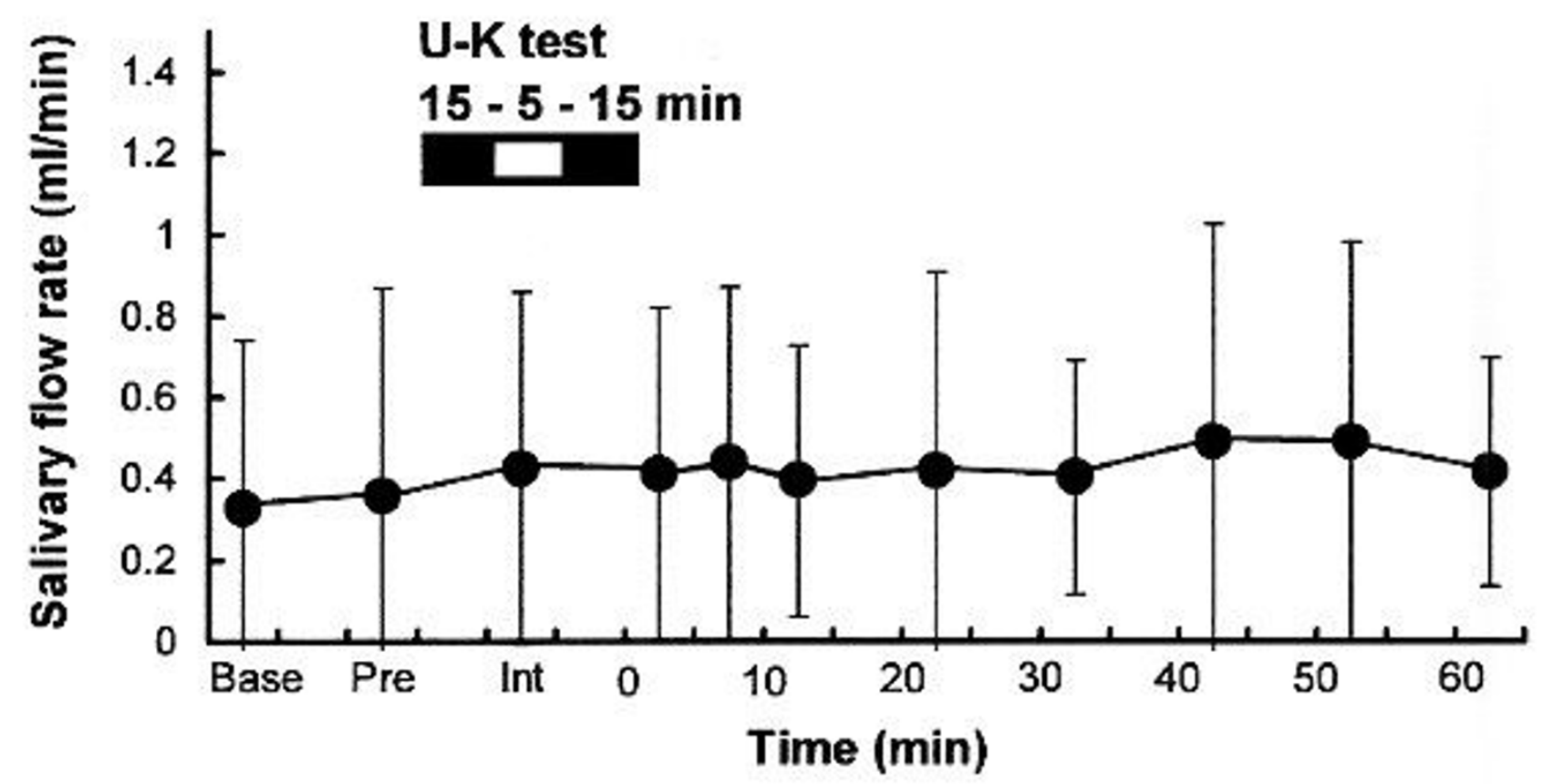

Figure 3

Salivary flow rate before and after the $\mathbf{U}-\mathbf{K}$ test. Data $(\mathrm{ml} / \mathrm{min})$ are mean \pm SD $(\mathrm{n}=16)$. Saliva was collected for 5 min by the spitting method. Base; basal state of volunteers I h before the U-K test; pre: immediately before the test; int: during the test interval; 0, 5, 10, 20, 30, 40, 50, 60 min: minutes after completion of the U-K test. U-K: Uchida-Kraepelin.

The U-K test does not influence salivary $\alpha$-amylase activity, chromogranin A or immunoglobulin A

Salivary AA activities were not significantly different between the reference range (Base) and the range before, during, and after the U-K test, as shown in Figure 4[A]. Similar findings were recorded for $\mathrm{sCgA}$ and sIgA concentrations before, during, and after the U-K test, as shown in Figure [4B and 4C]. Salivary AA: $[d f=10, F$-value $=0.56$, $P=0.84]$. Salivary CgA: $[d f=10, F$-value $=0.92, P=0.51]$. Salivary IgA: $[d f=10, F$-value $=0.34, P=0.97]$. Large interindividual variability was noted in sAA activity, sCgA and sIgA, and there were no statistically significant changes in these parameters. These results differ from those reported previously by others; eg, the U-K test or mental arithmetic test is reported to result in increases in sAA [7] and sIgA $[2,35,41]$.

\section{Psychological assessment of participants and the} relationship between their character and stress substances The psychological status of each participant was assessed by the analysis of SF-36 and the U-K test. No remarkable psychological patterns or character deviation were noted for the participants. None of the categories of the SF-36 or U-K test was correlated with plasma ACTH, DA, NA, or AD concentration or with salivary AA, CgA, or AA (data not shown).

\section{Discussion}

The U-K test given to the young women studied induced no significant changes in any of the reported markers of psychological/mental stress, i.e., plasma ACTH and catecholamines. In general, ACTH is up-regulated through the HPA axis under stress conditions, often accompanied by secretion of AD and NA from the adrenal medulla and sympathetic nerve terminals [7,13-16]. In fact, the Trier Social Stress Test (TSST) induced up-regulation of plasma ACTH until 30-40 min after the stress [42,43], although plasma DA, NA and AD have not been measured as stress markers. Therefore, it seems that the U-K test did not affect the HPA and/or SAM system of the participants of our study. Dickerson and Kemeny [39] described that though acute psychological stressors can elicit cortisol and ACTH activation, not all acute psychological stressors provoke this system. There is a substantial degree of variability in the size of cortisol and ACTH effects, depending on the characteristics of the stressor. Our results do not contradict the study of Dickerson and Kemeny [39]. The U-K test may have borderline value as a stress task because they categorized the U-K test as a cognitive task in which cortisol has little effect. In this study, there may be problem in that our experiment was done with a limited population of young women. However, Takai et al. [16] recently investigated gender differences in the activities of the HPA 

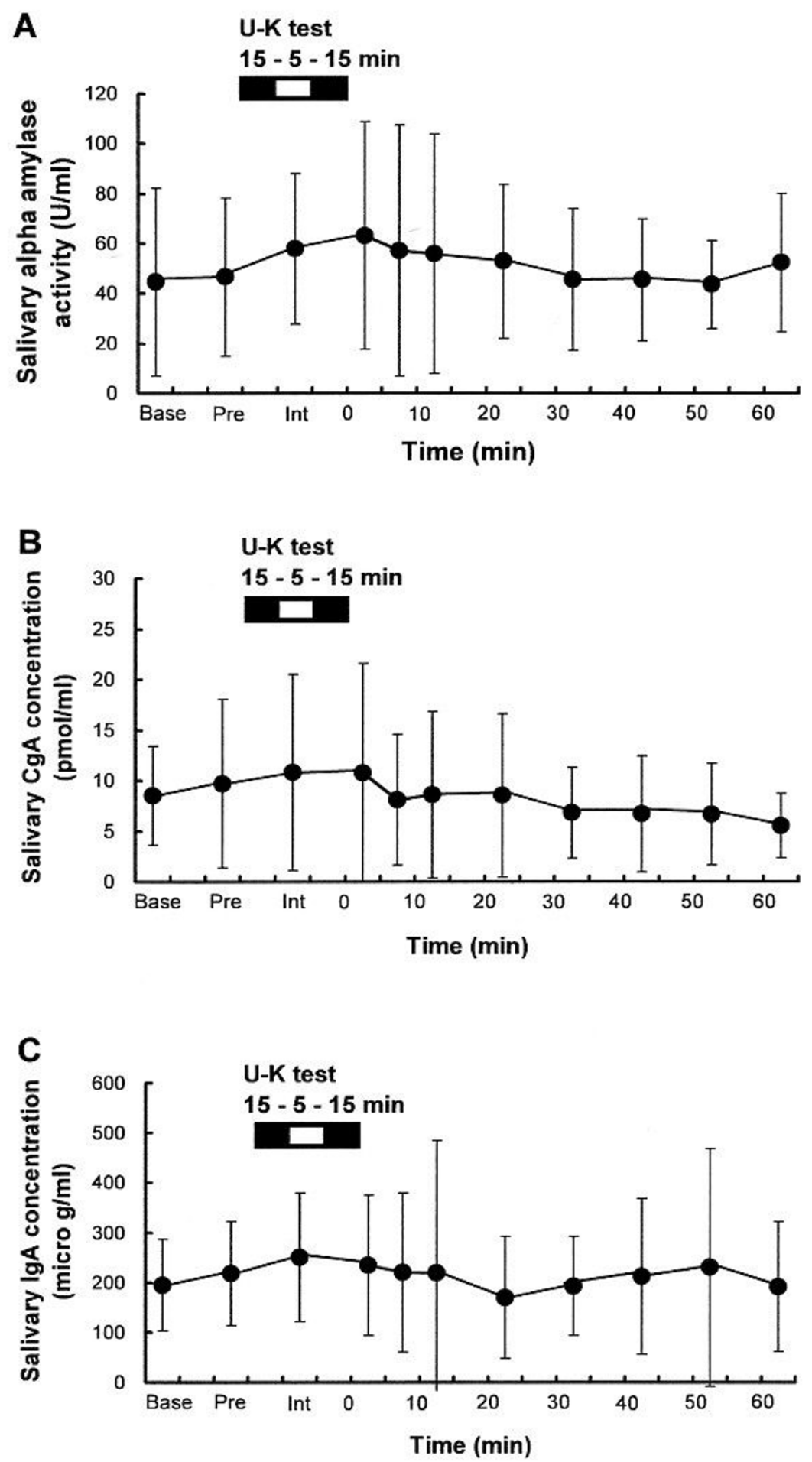

Figure 4

Salivary concentrations of $[A] \alpha$-amylase activity, $[B]$ chromogranin $A$, and $[C]$ immunoglobulin $A$ before and after the U-K test. Data $([A] \mathrm{U} / \mathrm{ml},[B] \mathrm{pmol} / \mathrm{ml},[\mathrm{C}] \mu \mathrm{g} / \mathrm{ml})$ are mean $\pm \mathrm{SD}(\mathrm{n}=16)$. Saliva was collected for $5 \mathrm{~min}$ by the spitting method. Base; basal state of volunteers I $\mathrm{h}$ before the U-K test; pre: immediately before the test; int: during the test interval; 0, 5, 10, 20, 30, 40, 50, 60 min: minutes after completion of the U-K test. U-K: Uchida-Kraepelin, CgA: chromogranin, IgA: immunoglobulin $A$. 
and SAM systems in response to acute psychological stress. They found no gender differences in the resting salivary cortisol and amylase levels. Furthermore, there were no gender differences in the salivary amylase level after stressful video viewing. Taken together, we do not recommend the use of the U-K test, at least for young women, for inducing psychological/mental stress, despite many reports of such an application [2,4-12].

The mean salivary flow rate of our participants was $0.33 \pm$ $0.41 \mathrm{ml} / \mathrm{min}$ by the passive spitting method. This rate is consistent with that reported in previous studies [20$22,24,33,44]$. In this study, we used the spitting method for saliva collection in preference to salivettes ${ }^{\circledR}$ cotton (Sarstedt, Numbrecht, Germany) to avoid mechanical stimulation of salivary secretion. One recent study compared the two methods and found no difference in mean saliva volume collected [45]. In contrast, another study showed that the relative increases in flow rate induced by psychological stress were significantly higher in saliva obtained by the spitting method than in that collected using salivettes cotton, although the saliva flow rate was not significantly different between the two methods under non-stress conditions [22]. Moreover, the cotton method caused substantial interference to many biomarker assays, including sIgA, giving falsely low readings due to the absorbent materials $[45,46]$. We therefore chose not to use the salivettes cotton method, and followed an earlier recommendation to use the spitting method for both unstimulated and stimulated whole saliva collection [47]. After all, the flow rates were not altered by the U-K test, arguing against any stress effect of the test on sAA, sCgA, or sIgA secretion.

No changes in salivary $\mathrm{AA}, \mathrm{CgA}$, and IgA concentrations were induced before during and after the U-K test. Goi et al. [2] studied the effect of the U-K test on salivary flow rate, sIgA, and sAA at short time points; $30 \mathrm{~min}$ and immediately prior to the test, as well as immediately and $30 \mathrm{~min}$ after the test. Only salivary flow rate $30 \mathrm{~min}$ after the U-K test and sIgA immediately after were increased over the 30-min-prior readings. The above study had a different methodology than ours; the authors used cotton for salivary collection with rough time points and a quantitative kinetic method to assay sAA.

Salivary AA is a potentially useful and easily collectable surrogate marker of the SAM system [48]. Rapid activation and recovery of SAA secretion is thought to characterize the response of the SAM system to stress [23]. Table 1 shows the levels of sAA under resting or pre-stress conditions reported in previous studies. The data show large variability among the studies. There was marked individual variation of sAA among the subjects tested [38], and relative diurnal variations reported for sAA $[17,22]$ and
sIgA [20]. Individual differences in sAA are related to age and pubertal development, and the level may be sensitive to specific experiences that involve physical, social, and cognitive demands [23]. This may explain the lack of normal range specified for sAA.

$\mathrm{CgA}$ is a major soluble protein in adrenal chromaffin cells and adrenergic neurons. It belongs to a family of highly acidic proteins, the chromogranins, which are co-stored and co-released with AD and NA in the adrenal medulla [49], and secreted with the catecholamines into the circulation [50]. Moreover, CgA is a valuable indicator of SAM activity [51]. Human CgA is produced by the submandibular glands and secreted into saliva [52]. Salivary CgA is considered a marker of sympathetic nervous activity including the SAM system [53]. Table 1 also lists the reported sCgA levels measured at rest or before stress. Our sCgA values measured during the non-stress periods were higher than those reported in two previous studies, and this difference could be due to the use of different collection methods. Moreover, the secretory pattern of sCgA follows circadian rhythms [54]. Like sAA, a normal range for human $\mathrm{sCgA}$ also remains to be specified.

Salivary IgA is a convenient and commonly used indicator of immune status. This parameter reportedly indicates the functional status of the entire mucosal immune system [55]. Numerous studies have shown that sIgA is sensitive to psychological variables. Early studies explored the relationship between sIgA and long-term psychological stress or in individuals particularly prone to stress [56]. Such studies consistently revealed stress-related down-regulation of sIgA [57]. This evidence supports the argument that prolonged psychological stress can compromise certain aspects of immune function [56]. Paradoxically, acute responses to a psychological challenge include a rise in sIgA concentration [58]. This mobilization of sIgA has also been reported in response to acute laboratory psychological stress tests including mental arithmetic tests $[35,41]$. However, there is little information on whether or not sIgA secretion is affected by psychological stress, or how that might occur mechanistically. An association was demonstrated between psychological activation of the HPA axis and the modulation of sIgA [59,60]. However, these studies showed opposite correlations of salivary cortical and sIgA response. Moreover, the non-stress sIgA values varied between studies (Table 1) [61-66]. Our results were compatible with the expected range reported in the kit instructions, making our sIgA data more reliable.

Salivary IgA is produced by plasma cells located adjacent to the salivary gland ducts and acini [67]. The sIgA response to oral antigens may be induced via two mechanisms: stimulation of the response directly following the proliferation and differentiation of local lymphoid cells, 
Table I: Values and methods from previous reports for the determination of representative salivary stress markers during a non-stress period

\begin{tabular}{|c|c|c|c|c|c|}
\hline Salivary stress marker & Reference & ValueI & $\mathbf{n}$ & Measurement method & Salivary collection method \\
\hline \multirow[t]{19}{*}{$\mathrm{sAA}(\mathrm{U} / \mathrm{ml})$} & {$[2]$} & $39.1-309.1 *$ & 39 & EKM & cotton \\
\hline & {$[17]$} & $15-365(14-16$ PM) & 76 & EKM & cotton \\
\hline & {$[18]$} & $60-200$ & 12 & EKM & cotton \\
\hline & {$[48]$} & $30-60$ & 15 & EKM & cotton \\
\hline & {$[61]$} & $20-230$ & 12 & EKM & cotton \\
\hline & {$[62]$} & $40-150$ & 13 & EKM & cotton \\
\hline & {$[22]$} & $9-50$ & 26 & EKM & Cotton \\
\hline & & $0-27$ & 26 & & passive spitting \\
\hline & {$[16]$} & male $63.6-179.4$ & 18 & EKM & passive spitting \\
\hline & & female $81 . \mid-183.1$ & 14 & & \\
\hline & {$[19]$} & $7.8-76.6$ & 20 & EKM & passive spitting \\
\hline & {$[20]$} & $290-700$ & 8 & EKM & passive spitting \\
\hline & {$[21]$} & $21.2-149.8$ & 67 & EKM & passive spitting \\
\hline & {$[24]$} & males $50.9-192.1$ & 53 & EKM & passive spitting \\
\hline & & females $58.2-190.3$ & 30 & & \\
\hline & [63] & $0-50$ & 13 & EKM & passive spitting \\
\hline & [7] & $2.6-65.0$ & 11 & DCS** & test-strip \\
\hline & [38] & $9.5-43.4$ & 15 & DCS** & test-strip \\
\hline & this report & $6.9-82.2$ & 16 & DCS** & test-strip \\
\hline \multirow[t]{3}{*}{ sCgA (pmol/ml) } & {$[54]$} & $0.2-0.4$ & 40 & ELISA** & cotton \\
\hline & {$[64]$} & $1.2-2.4$ & 11 & ELISA** & cotton \\
\hline & this report & $3.6-13.4$ & 16 & ELISA** & passive spitting \\
\hline \multirow[t]{6}{*}{$\operatorname{slgA}(\mu g / m l)$} & {$[2]$} & $4.65-15.05$ & 39 & ELISA & cotton \\
\hline & {$[32]$} & $28.7-92.7$ & 27 & ELISA & cotton \\
\hline & [35] & $7.6-132.4$ & 27 & ELISA & cotton \\
\hline & {$[56]$} & $6.4-17.7$ (PM sampling) & 8 & ELISA & cotton \\
\hline & {$[65]$} & $9-11$ & 16 & ELISA & cotton \\
\hline & {$[66]$} & $186.7-653.4$ & 18 & ELISA & cotton \\
\hline
\end{tabular}


Table I: Values and methods from previous reports for the determination of representative salivary stress markers during a non-stress period (Continued)

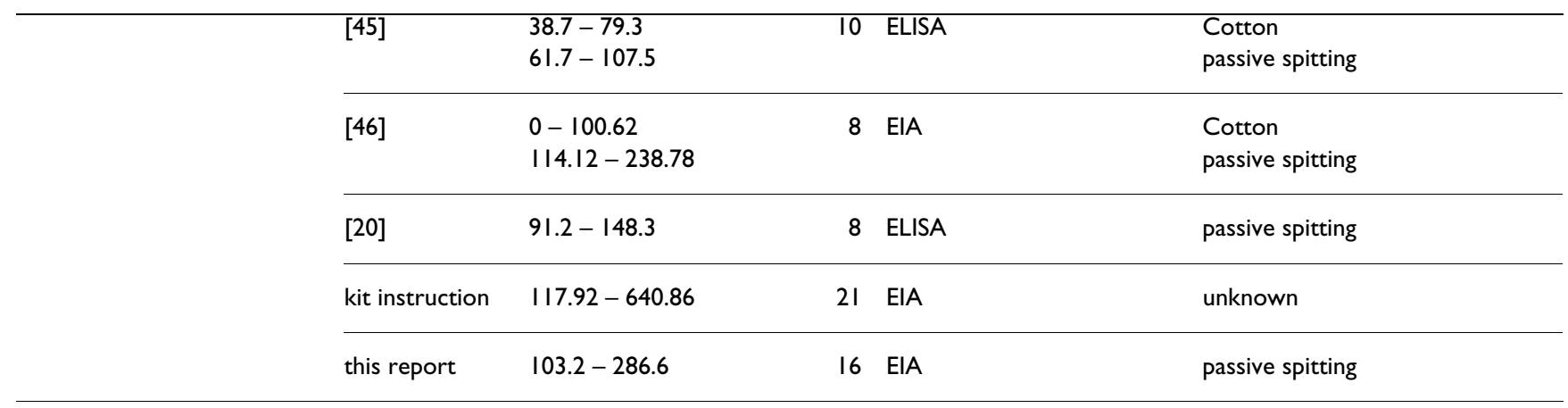

TValues are mean \pm SD.

*The mean sAA value in the original report (Goi et al., 2007) was $17.41 \pm 13.50\left( \pm \mathrm{SD}, \times 10^{4} \mathrm{U} / \mathrm{ml}\right)$, however this value was probably an incorrect calculation. In this table, we multiplied the original value by $10^{-3}$.

** Our measurement is similar to that recommended by the manufacturers.

sAA: salivary alpha amylase, sCgA: salivary chromogranin A, slgA: salivary immunoglobulin A, EKM: enzyme kinetic method, DCS: dry chemistry

system, EIA: enzyme immunoassay, ELISA: enzyme-linked immunosorbent assay.

and the migration of antigen-sensitized IgA precursor B cells from gut-associated lymphoid tissue to salivary glands [67] (and references therein). Further investigations of the association between sIgA and the stress response as well as the mechanisms involved are clearly needed.

Many scientists have used the U-K test as a psychological/ mental stressor. Our results indicate, however, that the U$\mathrm{K}$ test should be employed carefully as a psychological/ mental stressor due to insufficient scientific evidence of its effectiveness. In addition, salivary $\mathrm{AA}, \mathrm{CgA}$, and IgA are probably not suitable candidate markers of psychological/ mental stress, because the mechanism of stress-induced secretion and their normal ranges remain to be specified.

\section{Conclusion}

The U-K test has been regarded as a psychological/mental stress inducer. We measured the serial changes in plasma $\mathrm{ACTH}, \mathrm{DA}, \mathrm{NA}$, and $\mathrm{AD}$ levels, as well as salivary AA, CgA, and IgA concentrations before, during and after conducting a U-K test. None of these stress substances changed in response to the test, suggesting that it does not elicit the HPA axis and/or SAM system stress response. Therefore, the U-K test does not seem to be an appropriate psychological/mental stressor. In addition, salivary AA, CgA, and IgA should not simply be compared with previous reports, because the mechanism of secretion and normal range of each salivary parameter remain unknown. Salivary AA, $\mathrm{CgA}$, and IgA may not be suitable candidate markers of psychological/mental stress. Since the present experiment was done only with young women, further studies of other populations are necessary.

\section{Competing interests}

The authors declare that no financial support or compensation has been received from any individual or corporate entity for research or professional service and there are no personal financial holdings that could be perceived as constituting a potential conflict of interest.

\section{Authors' contributions}

KS and NS designed the protocol, performed the statistical analysis, and wrote the manuscript. AK and KS carried out the assay of plasma and salivary stress substances. NS and others participated in the human experiment.

\section{Acknowledgements}

We greatly appreciate the participation of the volunteers in this study. We also thank Dr. Eriko Kasahara for her support during the course of the study.

This work was carried out at the Kansei Fukushi Research Center of Tohoku Fukushi University, Sendai, Japan. Funding for this study was provided by the "Academic Frontiers" Project for Private Universities: a matching fund subsidy from the Ministry of Education, Culture, Sports, Science and Technology of Japan (2004-2008), and was also supported by Research Grants for Scientific Research (C) 18592066 and (C) 1959240I from the Ministry of Education, Culture, Sports, Science and Technology (20062008). These grants had no further role in the study design; in the collection, analysis and interpretation of data; in the writing of the report; or in the decision to submit the paper for publication.

\section{References}

I. Kashiwagi S, Yanai H, Aoki T, Tamai H, Tanaka Y, Hokugoh K: A factor analytic study of the items for the personality description based on the principle of the three traits theory for the work curve of addition of the Uchida-Kraepelin psychodiagnostic test. Shinrigaku Kenkyu (The Japanese journal of psychology) 1985, 56:179-182. (in Japanese)

2. Goi N, Hirai Y, Harada H, Ikari A, Ono T, Kinae N, Hiramatsu M, Nakamura K, Takagi K: Comparison of peroxidase response to mental arithmetic stress in saliva of smokers and non-smokers. J Toxicol Sci 2007, 32: 121-I 27. 
3. Li GY, Ueki H, Kawashima T, Sugataka K, Muraoka T, Yamada S: Involvement of the noradrenergic system in performance on a continuous task requiring effortful attention. Neuropsychobiology 2004, 50:336-340.

4. Negoescu R, Dinca-Panaitescu S, Filcescu V, lonescu D, Wolf S: Mental stress enhances the sympathetic fraction of $Q T$ variability in an RR-independent way. Integr Physiol Behav Sci 1997 32:220-227.

5. Dinca-Panaitescu S, Dinca-Panaitescu M, Achim A, Negoescu R: Idioventricular low frequency oscillation in $Q T$ interval responds univocally to RR confusing kinds of mental stress. Integr Physiol Behav Sci 1999, 34: 10-18.

6. Oishi K, Kamimura M, Nigorikawa T, Nakamiya T, Williams RE, Horvath SM: Individual differences in physiological responses and type A behavior pattern. Appl Human Sci 1999, 18:10I-108.

7. Yamaguchi M, Kanemori T, Kanemaru M, Takai N, Mizuno Y, Yoshida $\mathrm{H}$ : Performance evaluation of salivary amylase activity monitor. Biosens Bioelectron 2004, 20:49I-497.

8. Shimbo M, Kuroiwa C, Yokogoshi $\mathrm{H}$ : The effects of carbohydrate consumption on stress levels in humans. J Nutr Sci Vitamino 2004, 50:283-285.

9. Strelets VB, Garakh Zh V, Novototskii-Vlasov V: Comparative study of the gamma-rhythm in the norm, pre-examination stress and patients with the first depressive episode. Zh Vyssh Nerv Deiat Im I P Pavlova 2006, 56:2 19-227.

10. Yasumasu T, Reyes Del Paso GA, Takahara K, Nakashima $Y$ : Reduced baroreflex cardiac sensitivity predicts increased cognitive performance. Psychophysiology 2006, 43:41-45.

II. Sumiyoshi T, Saitoh O, Yotsutsuji T, Itoh H, Kurokawa K, Kurachi M: Differential effects of mental stress on plasma homovanillic acid in schizophrenia and normal controls. Neuropsychopharmacology 1999, 20:365-369.

12. Sumiyoshi T, Yotsutsuji T, Kurachi M, Itoh H, Kurokawa K, Saitoh O: Effect of mental stress on plasma homovanillic acid in healthy human subjects. Neuropsychopharmacology 1998, 19:70-73.

13. Johnson EO, Kamilaris TC, Chrousos GP, Gold PW: Mechanisms of stress: a dynamic overview of hormonal and behavioral homeostasis. Neurosci Biobehav Rev 1992, 16:1 I5-30

14. Habib KE, Gold PW, Chrousos GP: Neuroendocrinology of stress. Endocrinol Metab Clin North Am 200I, 30:695-728.

15. Black PH, Garbutt LD: Stress, inflammation and cardiovascular disease. J Psychosom Res 2002, 52:I-23.

16. Takai N, Yamaguchi M, Aragaki T, Eto K, Uchihashi K, Nishikawa Y: Gender-specific differences in salivary biomarker responses to acute psychological stress. Ann N Y Acad Sci 2007, 1098:510-515.

17. Nater UM, Rohleder N, Schlotz W, Ehlert U, Kirschbaum C: Determinants of the diurnal course of salivary alpha-amylase. Psychoneuroendocrinology 2007, 32:392-40I.

18. Chatterton RT Jr, Vogelsong KM, Lu YC, Ellman AB, Hudgens GA: Salivary alpha-amylase as a measure of endogenous adrenergic activity. Clin Physiol 1996, 16:433-448.

19. Skosnik PD, Chatterton RT Jr, Swisher T, Park S: Modulation of attentional inhibition by norepinephrine and cortisol after psychological stress. Int I Psychophysiol 2000, 36:59-68.

20. $L i \mathrm{TL}$, Gleeson M: The effect of single and repeated bouts of prolonged cycling and circadian variation on saliva flow rate, immunoglobulin $\mathbf{A}$ and alpha-amylase responses. J Sports Sci 2004, 22:1015-1024.

21. Gordis EB, Granger DA, Susman EJ, Trickett PK: Asymmetry between salivary cortisol and alpha-amylase reactivity to stress: relation to aggressive behavior in adolescents. Psychoneuroendocrinology 2006, 31:976-87.

22. Rohleder N, Wolf JM, Maldonado EF, Kirschbaum C: The psychosocial stress-induced increase in salivary alpha-amylase is independent of saliva flow rate. Psychophysiology 2006, 43:645-652.

23. Granger DA, Kivlighan KT, el-Sheikh M, Gordis EB, Stroud LR: Salivary alpha-amylase in biobehavioral research: recent developments and applications. Ann N Y Acad Sci 2007, 1098: I 22-I 44

24. Takai N, Yamaguchi M, Aragaki T, Eto K, Uchihashi K, Nishikawa Y: Effect of psychological stress on the salivary cortisol and amylase levels in healthy young adults. Arch Oral Biol 2004, 49:963-968.
25. Lee T, Shimizu T, lijima M, Obinata K, Yamashiro Y, Nagasawa S: Evaluation of psychosomatic stress in children by measuring salivary chromogranin A. Acta Paediatr 2006, 95:935-939.

26. Noto $Y$, Sato $T$, Kudo M, Kurata K, Hirota $K$ : The relationship between salivary biomarkers and state-trait anxiety inventory score under mental arithmetic stress: a pilot study. Anesth Analg 2005, I01:1873-1876.

27. Ng V, Koh D, Mok BY, Chia SE, Lim LP: Salivary biomarkers associated with academic assessment stress among dental undergraduates. J Dent Educ 2003, 67:1091-1094.

28. Miyakawa M, Matsui T, Kishikawa H, Murayama R, Uchiyama I, Itoh T, Yoshida T: Salivary chromogranin $A$ as a measure of stress response to noise. Noise Health 2006, 8: I08-II3.

29. Kanamaru Y, Kikukawa A, Shimamura K: Salivary chromogranin$A$ as a marker of psychological stress during a cognitive test battery in humans. Stress 2006, 9:|27-|3|.

30. Lowe G, Urquhart J, Greenman J, Lowe G: Academic stress and secretory immunoglobulin A. Psychol Rep 2000, 87:721-722.

31. Hucklebridge F, Lambert S, Clow A, Warburton DM, Evans PD, Sherwood N: Modulation of secretory immunoglobulin A in saliva; response to manipulation of mood. Biol Psychol 2000, 53:25-35.

32. Deinzer R, Kleineidam C, Stiller-Winkler R, Idel H, Bachg D: Prolonged reduction of salivary immunoglobulin A (slgA) after a major academic exam. Int J Psychophysiol 2000, 37:219-232.

33. Miletic ID, Schiffman SS, Miletic VD, Sattely-Miller EA: Salivary IgA secretion rate in young and elderly persons. Physiol Behav 1996, 60:243-248

34. Otsuki T, Sakaguchi H, Hatayama T, Takata A, Hyodoh F, Tsujita S, Ueki A, Morimoto K: Secretory IgA in saliva and academic stress. Int J Immunopathol Pharmacol. 2004, I 7(Suppl 2):45-48.

35. Willemsen G, Ring C, McKeever S, Carroll D: Secretory immunoglobulin $A$ and cardiovascular activity during mental arithmetic: effects of task difficulty and task order. Biol Psychol 2000, 52:|27-|4|.

36. Ohira $\mathrm{H}$ : Social support and salivary secretory immunoglobulin A response in women to stress of making a public speech. Percept Mot Skills 2004, 98: 124I-1250.

37. Fukuhara S, Suzukamo Y: SF-36v2 ${ }^{\mathrm{TM}}$ (Japanese version) Tokyo: iHope International; 2004

38. Yamaguchi M, Deguchi M, Wakasugi J, Ono S, Takai N, Higashi T, Mizuno $Y$ : Hand-held monitor of sympathetic nervous system using salivary amylase activity and its validation by driver fatigue assessment. Biosens Bioelectron 2006, 21:1007-10|4.

39. Dickerson SS, Kemeny ME: Acute stressors and cortisol responses: a theoretical integration and synthesis of laboratory research. Psychol Bull 2004, 130:355-391.

40. Ferguson DB: The flow rate and composition of human labial gland saliva. Arch Oral Biol 1999, 44(SuppI I):SI I-I4.

4I. Willemsen G, Ring C, Carroll D, Evans P, Clow A, Hucklebridge F: Secretory immunoglobulin $A$ and cardiovascular reactions to mental arithmetic and cold pressor. Psychophysiology 1998, 35:252-259.

42. Kudielka BM, Schommer NC, Hellhammer DH, Kirschbaum C: Acute HPA axis responses, heart rate, and mood changes to psychosocial stress (TSST) in humans at different times of day. Psychoneuroendocrinology 2004, 29:983-992.

43. Kirschbaum C, Pirke KM, Hellhammer DH: The 'Trier Social Stress Test' - a tool for investigating psychobiological stress responses in a laboratory setting. Neuropsychobiology 1993 , 28:76-8।

44. Nicolau J, Leite MF: In vitro and in vivo effects of fluoride solutions on human salivary amylase. Fluoride 200I, 34:55-60.

45. Michishige F, Kanno K, Yoshinaga S, Hinode D, Takehisa Y, Yasuoka S: Effect of saliva collection method on the concentration of protein components in saliva. J Med Invest 2006, 53: I40-I46.

46. Shirtcliff EA, Granger DA, Schwartz E, Curran MJ: Use of salivary biomarkers in biobehavioral research: cotton-based sample collection methods can interfere with salivary immunoassay results. Psychoneuroendocrinology 2001, 26:165-173

47. Navazesh M: Methods for collecting saliva. Ann N Y Acad Sci 1993 694:72-77.

48. van Stegeren A, Rohleder N, Everaerd W, Wolf OT: Salivary alpha amylase as marker for adrenergic activity during stress: effect of beta blockade. Psychoneuroendocrinology 2006, $31:|37-14|$ 
49. Blaschko H, Comline RS, Schneider FH, Silver M, Smith AD: Secretion of a chromaffin granule protein, chromogranin, from the adrenal gland after splanchnic stimulation. Nature 1967, 2 I 5:58-59.

50. Winkler H, Fischer-Colbrie R: The chromogranins A and B: the first 25 years and future perspectives. Neuroscience 1992, 49:497-528.

51. Taupenot L, Harper KL, O'Connor DT: The chromogranin-secretogranin family. N Engl J Med 2003, 348: I I34-I I 49.

52. Saruta J, Tsukinoki K, Sasaguri K, Ishii H, Yasuda M, Osamura YR, Watanabe $Y$, Sato S: Expression and localization of chromogranin A gene and protein in human submandibular gland. Cells Tissues Organs 2005, I 80:237-244.

53. Nakane H, Asami O, Yamada Y, Harada T, Matsui N, Kanno T, Yanaihara N: Salivary chromogranin A as an index of psychosomatic stress response. Biomed Res 1998, 19:401-406.

54. Den R, Toda M, Nagasawa S, Kitamura K, Morimoto K: Circadian rhythm of human salivary chromogranin A. Biomed Res 2007 , 28:57-60.

55. Mestecky J: Saliva as a manifestation of the common mucosal immune system. Ann N Y Acad Sci 1993, 694:184-194.

56. Hucklebridge $F$, Clow A, Evans $P$ : The relationship between salivary secretory immunoglobulin $A$ and cortisol: neuroendocrine response to awakening and the diurnal cycle. Int J Psychophysiol 1998, 3 I:69-76.

57. Evans P, Hucklebridge FH, Clow A, Doyle A: Secretory immunoglobulin $A$ as a convenient biomarker in health survey work. In Health psychology and quality of life research Edited by: Rodrigues M. Spain: Health Psychology Dept., University of Alicante; 1995:541-549.

58. Evans P, Clow A, Hucklebridge FH: Stress and the immune system: current issues and directions in research. Psychologist 1997, 10:303-307.

59. Zeier $\mathrm{H}$, Brauchli $\mathrm{P}$, Joller-Jemelka $\mathrm{HI}$ : Effects of work demands on immunoglobulin A and cortisol in air traffic controllers. Biol Psychol 1996, 42:413-423.

60. Evans P, Bristow M, Hucklebridge F, Clow A, Pang FY: Stress, arousal, cortisol and secretory immunoglobulin $A$ in students undergoing assessment. Br J Clin Psychol 1994, 33:575-576.

61. Rohleder N, Nater UM, Wolf JM, Ehlert U, Kirschbaum C: Psychosocial stress-induced activation of salivary alpha-amylase: an indicator of sympathetic activity? Ann N Y Acad Sci 2004, 1 032:258-263.

62. Nater UM, Rohleder N, Gaab J, Berger S, Jud A, Kirschbaum C, Ehlert $\mathrm{U}$ : Human salivary alpha-amylase reactivity in a psychosocial stress paradigm. Int J Psychophysiol 2005, 55:333-342.

63. Ehlert U, Erni K, Hebisch G, Nater U: Salivary alpha-amylase levels after yohimbine challenge in healthy men. J Clin Endocrinol Metab 2006, 9 1:5130-5133.

64. Toda M, Kusakabe S, Nagasawa S, Kitamura K, Morimoto K: Effect of laughter on salivary endocrinological stress marker chromogranin A. Biomed Res 2007, 28: II5-II8.

65. Clow A, Lambert S, Evans P, Hucklebridge F, Higuchi K: An investigation into asymmetrical cortical regulation of salivary $S$ IgA in conscious man using transcranial magnetic stimulation. Int I Psychophysiol 2003, 47:57-64.

66. Tsuboi H, Hamer M, Tanaka G, Takagi K, Kinae N, Steptoe A: Responses of ultra-weak chemiluminescence and secretory IgA in saliva to the induction of angry and depressive moods. Brain Behav Immun 2008, 22:209-214.

67. Marcotte $H$, Lavoie MC: Oral microbial ecology and the role of salivary immunoglobulin A. Microbiol Mol Biol Rev 1998, 62:71-109.
Publish with Bio Med Central and every scientist can read your work free of charge

"BioMed Central will be the most significant development for disseminating the results of biomedical research in our lifetime. "

Sir Paul Nurse, Cancer Research UK

Your research papers will be:

- available free of charge to the entire biomedical community

- peer reviewed and published immediately upon acceptance

- cited in PubMed and archived on PubMed Central

- yours - you keep the copyright

Submit your manuscript here:

http://www.biomedcentral.com/info/publishing_adv.asp
BiolMedcentral 